\title{
Best Manufacturing practice adoptions by Indian Industries
}

\author{
${ }^{1} \mathrm{R}$ Nesamoorthy , ${ }^{2}$ Manvijay Singh \\ ${ }^{l}$ Department of Mechanical Engineering, Dr K N Modi University, Newai, Rajasthan \\ ${ }^{2}$ Department of Mechanical Engineering, Dr K N Modi University, Newai, Rajasthan
}

\begin{abstract}
The purpose of this study is to develop a new model to provide guidance and support for Indian manufacturing companies who aim to reach at global level standards both in maintenance and manufacturing processes through continual improvement. Based on this study, a strategic model was developed through conceptual integration of popular process improvement strategies, which are based on ISO, TQM, TPM , Lean Production, six-sigma \& TPM. An attempt was made to analyze and address some major limitations of existing models to pave the way of achieving manufacturing excellence.
\end{abstract}

Keywords:Manufacturing, Kaizen, JIT, six-sigma, lean, Agile manufacturing, TQM, total productive maintenance, world-class, model.

\section{INTRODUCTION}

The word "World Class" was coined by Hayes \& Wheelwright (1984) to describe the capabilities of an organization which follows certain proven methodologies by similar companies. Japan has been considered as the model of best practice using countries in manufacturing after the World War I (Tauguchi et all). It goes without saying that, becoming a world-class manufacturing (WCM) company is a common industrial goal. Many companies are trying to adopt this philosophy in their production process to be the best in the world within their particular sector of industry. Kodali et al. (2004), by performing a comprehensive performance value analysis on WCM and other advanced manufacturing system such as job shop (JS), agile manufacturing, transfer line (TL), computer integrated manufacturing (CIM) Systems and group technology(GT) demonstrated that the WCM is the best alternative for implementation and to achieve or maintain competitive advantages. A review of the literature shows that there is no universally recognized definition of WCM and different researchers have different views about WCM as the best manufacturing practice varies from organization to organization. The problem which is common in attempts of defining the concept of world class manufacturing is how to interpret the measures within the operating context of the firm (Harrison, 1998). However, the description of WCM by Sinha and Sinha (2007) can be a clue for understanding the scope of WCM concept. They stated that the term WCM is applied for organizations that achieved a global competitive advantage through the use of best practice manufacturing capabilities. This improved competitiveness in the broadest sense is referred to as manufacturing excellence and is deemed to be demonstrated by simultaneous improvements in manufacturing performance as well as business performance through indicators, such as productivity, cost reduction and market share. If the firm continues to excel in manufacturing, it may dominate world markets, in which case it would be called a world class manufacturer. Coping with the ever changing conditions of today's markets have led to significant emphasize on production flexibility. In this regard, traditional manufacturing practices have been replaced with highly automated processes and also application of Lean and just-intime (JIT) production strategies have led to minimum inventory buffers. In such environment, reaching to superior performance in manufacturing requires near 100 percent uptime. On the other hand, without excessive inventory buffers, unscheduled equipment downtime usually costs 10 to 20 times what the same equipment downtime costs in old traditional batch processing or functional departments (Cooper, 2004). This is due to the fact that each equipment failure could results directly and immediately in lost sale opportunity, failed shipping schedules and loss in customer satisfaction. Hence, it is also becoming increasingly difficult to ignore the role of maintenance on the way of manufacturing excellence. In fact, reaching to world-class performance in maintenance is an important prerequisite for WCM since there is a direct relationship between these two that without one, reaching to second would face serious problems. So far, most studies in the field of world-class have only focused on manufacturing, and researchers have not treated "world class concept in maintenance in much detail. Mostly each of them has studied predominantly as independent methods based on 
specific situations in application. Hence, this paper aims to examine the integration of these popular process improvement.

\section{REVIEW OF EXISTING MODELS}

Embarking on a journey towards WCM without precise roadmap is very risky according to Sharma and Kodali (2008, p. 51), lack of "practical pursuit of excellence within manufacturing." So far, many researchers have realized the importance of this issue and developed models to assist organizations in the way of reaching to their manufacturing performance objectives. However, most of the early models could not be used due to narrow elements' consideration. Gradually, the WCM models were improved by covering more detailed conditions but yet could address only the issues pertaining to individual industry. Schonberger (1986) is known as one of the pioneers in devising WCM models and in which he devised first integration of tools to achieve the overall performance. However, according to Nachiappan et al. (2009), implementation of JIT at the beginning stage of the model, un-clarified method and sequence of implementation can cause failure in many industries. Schonberger (1996) also introduced 16 principles of customer-focused " or" principlesbased management" that firms can use as WCM achievement criteria. For each of the 16 principles, there is a five-point scale, with 5 being the highest level of attainment. Any firm that scores more than 67 points is thought to be in the stage of maturity. Although, it is argued by Muda and Hendry (2002) that scoring systems such as that suggested by Schonberger (1996) can lead to misleading results if some of the underlying assumptions do not apply to particular types of company. Gunn (1987) presented another simple model that relies on three pillars: computer integrated manufacturing (CIM), total quality control/management (TQC/TQM) and JIT production methods. He believed that these are three fundamental approaches in modern manufacturing, which may enable an organization to gain competitive. Farsijani and Carruthers (1996) also developed a WCM through a conceptual model for their successful model which shows the growth of techniques and factors integration. Associated with the concept of WCM, this model is the remainder of this paper is organized as follows: actually an upgraded toolbox from 1980 onwards, with first, a review of the literature in relation to integration of respect to the industrial environment and organizational Secondly, an overview about current WCM models to achieve a better understanding of existing models was provided. In addition, the design and development of an integrated Lean Sigma Productive Maintenance (LSPM) model was chronicled. Also, the evaluation of the model for its effectiveness through comparative analysis comprehensive researches to provide a model for management principles and resources and also key initiatives for organizations to be world class. A total of 23 models and around 252 unique elements of WCM were participated in their analysis. Based on the comparison, it was found that only a few of the models are similar and in the majority of the models, the naming and number of elements differ significantly. So they classified the 12 pivotal elements as pillars of WCM based on the frequency of participation in different models and the rest as sub-elements which were grouped under various pillars. However, it is argued by Nachiappan et al. (2009) that WCM models which are proposed by different authors have followed the trial-and-error approach, and they just cover need-based requirements. They also added that lack of clear consensus and systematic reason or background in the process of selection of tools to form WCM models, has resulted in an inconsistency between different tools and techniques, and increased the chance of unavailing implementation in various conditions. Therefore, in order to minimize the number of tools which constitute WCM model and yet maximize the effectiveness of their combination, a statistical survey was conducted in a leading multinational automotive company in India on 10 most recognized WCM tools. The results showed that the combination of total Quality Management (TQM), total productive maintenance (TPM), sixsigma and lean manufacturing gain more than 40 percent weight in addressing manufacturing system requirement for achieving world- class status. They also concluded that each of these three tools individually has more contributions in basic components of manufacturing systems (man, machine, method, material and operating environment) in comparison with the remaining seven WCM tools. According to Ross (1991), in order to achieve the world-class status, the number of tools and elements employed in the organization must be minimum in number and maximum in effect. Hence, it can be concluded that the model developed by Nachiappan et al. (2009) is the most effective one; so it was taken as a starting point in developing a new model based on the concepts of TQM/TPM, six-sigma and lean. In this report, the synergistic effects of these methodologies were investigated. From the literature survey, it is inferred that direct application of current WCM models may be faced with some major limitations. The limitations may be caused by pillars of a model, or type of industry for which the model is designed. In other words, the applied strategies of each model could influence the performance and universality of the WCM model. 
Consequently, the focal point of this study is to develop a new model to rectify the deficiencies of previous studies. This model is supposed to have some critical features such as being easy to apply; being able to restrict implementation costs based on certain circumstances of a company in terms of size, skill and industry; being intelligible for everyone who is involved in the process and increasing overall efficiency of technical systems. The model will be evaluated subsequently for its effectiveness, through verification of benefits and strengths of the new model compared with current similar models.

\section{MODEL STRATEGIES}

\section{Integration of six-sigma and lean}

Both lean and six-sigma are two recognized business process improvement strategies which are adopted by many organizations for achieving superior performance in quality, cost and time of manufacturing operations (Thomas et al., 2008; Kumar et al., 2006). But lean and six-sigma approaches have often been used in separation or sequential manner (Smith, 2003), which causes establishing two different ways to reaching one goal that results in a conflict of interest and consuming resources ineffectively or excessively (Bendell, 2006). In addition, over the last decades, many organizations have deployed either six-sigma or lean and tried to renovate their operating and supporting systems based on these strategies. After achieving initial rapid growth in market share and competitive advantages, gradually the velocity of this growth has reached to a point of diminishing return in such a way that further improvements are not readily generated. Hence, these organizations have faced with the necessity of finding another source of competitive advantage (Arnheiter and Maleyeff, 2005). Therefore, once the apparent benefits of lean and sixsigma were brought to the attention of the business world, lean and six-sigma practitioners integrated the two strategies into a more powerful and effective hybrid way, overcoming the limitations and retaining most of the strengths of each strategy. The phrase- Sigma \& Lean is to describe the integration of lean and six-sigma philosophies (Sheridan, 2000). There is little literature available on the integration of these concepts when looking for a "common model, the mutual content or method" (BeWheat et al. (2003) stated that both lean and six-sigma have some similarities in their ultimate goal, which help six-sigma to have a complementary role for Lean philosophy in such a way that provides tools and procedures to overcome specific problems along Lean journey. Pepper and Spedding (2010) mentioned that using either one of them alone has limitations; while Six- Sigma will eliminate defects, it will not address the question of how to optimize process flow. Furthermore, six- sigma in itself does not consider the needs of customers and can be said that it has been potential to lose sight of the customer if not implemented along lean principles. On the other hand, lean principles exclude the advanced statistical tools often required to achieve the scales sensitivity to small changes duplication of RPN reliability, has adopted different approaches from time-based maintenance (PM) and condition monitoring methods to the recent maintenance approaches that focus more on application of risk measuring methods in maintenance such as risk based inspection (RBI), periodic maintenance optimization (PMO), and reliability centered maintenance (RCM). By deep pondering upon these methods, it can be seen that all of them are based on subjective estimation of risk and prioritization via specific models and charts like failure mode effect analysis (FMEA) charts. However, FMEA charts with heavily relying on RPN methodology for ranking and assessing the risk of potential failure modes, have many defects that gradually are fading from the field of maintenance. According to Bowles (2004), although RPN technique is simple, easy to understand, straight forward to use and well documented from the management viewpoint, but from the technical perspective, it is seriously process capabilities needed to be truly 'Lean'. However, Arnheiter and Maleyeff, (2005) argued that a crucial aspect of integrating these two continuous improvement approaches is retaining equilibrium between them. The balance lies in creating sufficient value final product from manufactured the by customer's the company and viewpoint so that market share is maintained, while at the same time reducing variation to acceptable levels so as to lower costs incurred, without over-engineering the processes. Smith (2003) also represented some of the successful case studies in lean six-sigma application that the beneficiaries have experienced significant results from a combined approach to improvement. However, the main point in these case studies is that almost in all satisfactory experiences, one of the techniques became predominant over the other, on the way of improvement. Moreover, there is no specific model for answering the questions of where and in what applicable. Kumar et al. (2006) have also presented a case study undertaken by implementing a lean sigma model into an Indian small to medium sized enterprises (SME) in order to reduce the defects which occur in the thus satisfy their customers. They suggested that within SME environment, while lean organizes and simplifies the processes, tries to eliminate wastes, reduces overall complexity and helps to clarify value-added activities, sixsigma can solve complex cross functional problems where the root causes of a problem (in this case, crack propagation) is unknown 
and help to reduce undesirable variations in processes.the scales, sensitivity to small changes, duplication of RPN numbers and problems with comparing different RPNs. Bowles (2004) also argued that because of these deficiencies, the results of this technique are not only meaningless but are, in fact, misleading. So it is highly recommended to drop this approach and different prioritization technique being used. Deploying the concept of SixSigma into equipment reliability / maintenance applications has emerged lately, since this methodology has traditionally been limited to manufacturing and administrative processes (AlMishari and Suliman, 2008). Six- Sigma is considered as a strong alternative approach that mainly focuses on statistical deduction rather than subjective judgment. Hence, many researchers have been done to show the successful intervention of Six-Sigma in manufacturing, service sector (e.g. healthcare) and also for reliability applications (Revere, 2000). By comparing the six-sigma approach With existing methods Such as reliability centered Maintenance (RCM), it can be seen that unlike risk- centered methods, which focus on judgment, and unlike reliability/statistical analysis, which relies heavily on numerical data, six-sigma provides an integral mix of both valuable resources of information Al-Mishari and Suliman2008). Overall, review of recent works shows that sixsigma is appropriate to be used in maintenance management concept considering different aspects such as, statistical evaluation.

\section{Integration of TPM \& Lean:}

Both lean and TPM had evolved in parallel from their Early concepts and are coming together towards a common goal that is specifying areas of hidden wastes that is - any human activity, which absorbs resources but creates no value. Moreover, both are approaches that spanned all over the company and cover a wide Spectrum of techniques. They have both achieved significant results by delivering practical solutions to different business issues. Although the origin of them is different, having progress in each of them depends on clarifying wasteful behaviors and practices McCarthy and Rich, 2004). TPM acts as a bridge between lean Thinking and maintenance to improve efficiency and reduce wastes. This approach provides a synergistic relationship among all particularly between production and maintenance. Ferrari et al. (2002) have emphasized upon lean and TPM as two methodologies that can work together to provide a holistic approach to continuous improvement. While lean thinking tools improve the design efficiency of transformation processes that provide greater customer value with less effort (Womack and Jones, 1996), TPM tools enhance the effectiveness of this transformation process by improving capacity, increasing control and repeatability (Willmott and McCarthy, 2000). So synergy of the two approaches can develop both operational efficiency and organizational effectiveness. Hence, it can be concluded that each of six-sigma, lean and TPM has a significant synergistic effect on the others and when integrated in one model, can be substantially effective in addressing all types of process problems and necessary factors to achieve world-class status in both manufacturing and maintenance.

\section{Developing a New WCM Model}

Ensuring the availability and reliability of the equipment at the time of requirement, plays the most fundamental role in reaching to outstanding performance in manufacturing. So the journey towards excellence in manufacturing should be started from striving for reaching to world class maintenance. The term of world class when comes to maintenance, means the best model to reach the sixsigma level in maintenance of Rall,2005). Initially, it is necessary to consider company's mission statement a translating the mission and vision into a set of objectives and performance measures that can be quantified and appraised by using balanced scorecard methodology as a strategic management tool.

\section{Contribution of TPM and SIX-SIGMA}

Application of TPM concept in the process of reaching to World class maintenance is inevitable. Besides, the integration of six-sigma concept with TPM in the model is presented by using PDCA driven cycle called, DMAIC process of performances improvement. Six-Sigma forms the basic foundation for the TPM strategy and make it easier to understand by shop floor operators who are the most important enablers of successful TPM implementation. Within phases of DMAIC, various problems and circumstances of the maintenance department are defined, the performance of the process is measured, the most important causes of defects are analyzed, improvemen $\mathrm{t}$ or corrective actions are taken and the improvements are maintained by continuous controlling. Moreover, the iterative process of DMAIC is used as the main operational approach for the implementation of this model in order to have permanent improvement of maintenance activities and ideally the company's functions, but Reaching to Six-Sigma process performances. Furthermore, many six-sigma, lean and quality advanced supportive tools are used in the improvement process, to enhance the performance of both manufacturing and maintenance operations.

Adding Lean concept to the scenario 
Integration of TPM and Six-Sigma, which result in fewer variations in a process and reaching to process stability directly influences the effectiveness of lean implementation in eliminating wastes and reducing the amount of raw, WIP and finished goods inventories. Due to these complementary interactions, the proposed model is focused also on applying lean tools to maintenance as an effective way to promote these synergies, which is achieved by integrating Lean manufacturing and maintenance together. To this end, the concepts of lean, maintenance and reliability improvement was addressed simultaneously, in order to maximize the asset performance as the financial value generated by organization's facilities. to optimize the asset performance and equipment effectiveness in the model as a further step towards world class maintenance: process stabilization, reduction of inventory buffers and application of Lean manufacturing tools in a maintenance process

\section{Process stability \\ Unpredictable processes and/or high degree of downtime variance usually lead to inconsistency between cycle times of production units and time taken (that is the maximum time per unit allowed to produce a product in order to meet demand). This situation usually disturbs the balance of buffers, increases the waiting times between each stage of the process and most importantly, raises the need of investing on capital assets in order to cope with peak capacity requirements. Hence, by stabilizing of production process, an organization can benefit from shorter cycle time, smaller buffers and higher equipment effectiveness.}

\section{Inventory buffers}

So far, inventory buffers have not been considered as a maintenance and reliability improvement issue. But it must be considered that performing effective maintenance practices to enhance the reliability of production process can directly influence the amount of raw, WIP and finished inventory buffers (Finigan and Humphries, 2006). With application of lean tools and techniques in maintenance process three improvement opportunities will be achieved: (1) The buffers can be reduced due to high reliability of production units; (2) With a smaller buffer, the WIP parts spend less time in the buffers and as a result the processing time in each work station will be decreased, while in total, this reduction of lead time for each customer order, can provide a significant competitive advantage for the organization; (3) Smaller buffers can also reduce the probability of producing large amounts of defects prior to discovery at the next workstation due to many WIP in a buffer. Therefore, the costs of scrap and rework as two of the major manufacturing overhead costs can be substantially reduced.

\section{Lean tools}

In addition, application of five lean manufacturing tools which are embedded in the model has great compatibility with manufacturing operations as well. Hence, they can optimize both maintenance and manufacturing processes simultaneously. In general, these tools can be naturally fitted to every practice within an organization that wants to promote to Leanness. These tools include visual control, 5S, seven wastes, Single Minute Exchange of Dies (SMED) and PokaYoke (Doing things right First Time).

\section{FROM MANUFACTURING EXCELLENCE TO WCM}

Reaching to world class maintenance by integration of TPM, six-sigma and lean tools and techniques, predispose the development of world class manufacturing as ultimate objective. All too often, many advanced manufacturing technologies and techniques are deployed before deep analysis of the needs of the company owing to evolving prevalent misconception which for achieving world class standards, application of advanced technologies or high degree of automation are inevitable. However, without clear understanding of problems and barriers on the way of ultimate goals and also without clarifying the potential gap between current and desired future state of the company, superficial adaption of technological solutions may result in poor return of investment and other unfavorable results. Moreover, the process of adaptation must consider the size and skills available in various levels of the company. Today, many SMEs are among the topnotched companies, not because of implementing modern manufacturing facilities but due to having skillful employees, unique product features aimed at satisfying specific market needs, price range and flexible business strategies. In this regard, the model is extended to include a key strategy that when applied alongside Value Stream Mapping (VSM), Quality Function Deployment (QFD) and other value identification methodologies, can help to identify the gap between current and future state of organization, through measuring performance against world class standards. To this end, tools and methodologies of quality, lean and six-sigma is applied again in order to develop a pipeline of specific projects that will help to close the identified current and future gap. The main role of lean philosophy in this stage of an integrated improvement program is creating the basis and a foundation for improvement. In this way, 
the lean concept removes the dust of ambiguities from hidden costs and hidden non value-added activities, helping to reveal a realistic view of current state of organization which allows Six-Sigma to fill the business gaps faster and in a more efficient manner in subsequent steps. From another point of view, since some of the lean improvements occur virtually immediately compared to entire improvement project, observing the results of Lean projects can keep alive the momentum and motivation of employees to continue.. At the first step, lean introduces VSM as the central tool to develop a current state map which gives a holistic yet detailed look at the processes in the company which is essentially a snap shot capturing how things are currently being done. Analytical study of the current state map can disclose the weaknesses strengths in production flow from raw materials target product or service to the customers and driven towards the world class state.

Subsequently, the scope and boundaries of improvement should be defined by identifying the WCM criteria for specific industry in which the company with specific size and skill is operating. In fact, due to substantial increase in advanced manufacturing techniques, the only way to control the complexity and economic feasibility of the model is framing these advanced tools and techniques based on the needs of the company. Benchmarking of determinant features of current position such as business strategy, technology capabilities, work force skills and market share besides simplicity and sequential nature, the feedback- based nature of the process is particularly important to the company, which is essentially a snapshot capturing the company. By applying iterative process, management how things are currently being done can assess the suitability of potential solutions and any changes that have made in the process. Moreover, the model deploys seven key performance indicators information to delivery of (KPI) under quality, cost and delivery (QCD) metrics as suggested by UK Department of Trade and Industry (2004). The main reasons for choosing this specific metrics are high capability in simplifying the complex manufacturing process, providing rapid feedback and streamlining the process of benchmarking by providing a quantifiable numeric comparison. Table 3 outlines seven key measures and their potential impact on quality, cost and delivery. Each of these measures uses simple mathematical equation to analyze the performance of manufacturing system and provides results that can be used as the basis of continuous improvement.

\section{Model Verification}

Organization and by performing a series of activities; it continually improves towards WCM as ultimate objective. In many traditional organizations, the success of each department is measured independently and integration of each department with other departments ends where the boundaries of their respective responsibilities meet (Ross, 1991). Thus they need major alignment and critical infrastructures to become prepared for adoption of WCM concept. The new model emphasizes on full integration of all departments of organization, especially maintenance and manufacturing departments. Indeed without reaching to excellence in the maintenance process, struggling for WCM will be diminished to failure. Therefore, adaptation of this culture and values has conceptually embedded in the model. Moreover, successful application of WCM methodology requires roles and knowledge which may not be founded in the old organizations. So the concept of management commitment to the implementation of on-going training and skills improvement opportunities for employees is another underlying alignment for WCM, which is considered in the model. Furthermore, WCM requires a new operating culture which is related to elimination of wastes, identification of value-added manufacturing activities, reducing costs and commitment to quality. These issues are fundamental principles of WCM which are attained by placing Lean thinking as a pivotal concept in preparing both maintenance and manufacturing functions to promote to world class standards.

Potential benefits of many WCM models cannot be achieved due to forcing the users to implement many tools and techniques in the way of WCM. Excessive and unjustifiable use of tools intensifies the complexity of the model and necessitates consuming most of the resources of the company such as time, personnel, machines, etc., without considerable progress towards main objectives, which most of the times cause disappointment and frustration of the executives and employees and made them reluctant to continue. Keeping this fact in mind, the new model focuses on the implementation of TPM, Six-Sigma, TPM and Lean as three central tools, while other supporting tools can be applied to increase the efficiency of the process on an as-needed basis. The sequence and method of implementing these central tools have addressed precisely. For each phase of the change process, a detailed, step-by-step road map has been provided to help companies in the journey toward implementing and sustaining the model (Okhovat, 2010). Moreover, following a systematic procedure can result in a better understanding, direction and/or commitment and motivation from management. In parallel with implementation of three key components of the model, specific yet most effective tools from an advanced toolbox of quality 
management, six-sigma and lean, related to each phase is recommended in order to help users to achieve maximum outcomes and avoids them from the trial and error approach. In the way of reaching to WCM, defining right metrics to measure performance play a vital role. Simply put, only when right questions are asked, right answers can be found (Basu and Wright, 1996). Many performance measures have been suggested by different researchers in order to monitor and assess the achievements of the improvement process. By reviewing current models, it was noticed that almost all of them have used very general terms to measure the process which in turn may seem idealistic and unable to motivate both managers and employees of those organizations that initially started the journey towards WCM. Therefore, the proposed model has tried to cover this issue by developing an internal benchmarking approach that enables an organization to self-appraise against established WCM standards. In this regard, the model concentrates on quality, cost and delivery (QCD) outputs, which are seven quantitative measures as suggested by British Department of Trade and Industry (2004) (Table 3), and can be readily calculated, plotted and analyzed in a constant manner to provide rapid feedback to assess the results of any changes made in the production process. This can be effective to motivate the executives in placing more commitment to implementing the model by observing performance improvement trend. In addition, QCD measures can simplify a complex production process to establish a straightforward route for continual improvements.

\section{Benefits of New Model}

1) Establishing a structure for efforts of implementing manufacturing excellence.

2) All the advantages of TPM, lean and six-sigma are kept in tact in the model. These advantages are just integrated and systemized in order to reach world-class status.

3) Application of the new model can develop a culture of continuous improvement through reevaluation of appropriate performance measures both in the maintenance and manufacturing process. So, with every iteration of the model, a further step towards reaching WCM can be taken.

4) Coherent synthesis of six-sigma, TPM and lean by using structured DMAIC technique, can facilitate joint implementation of these systems in order to excel both maintenance and manufacturing process in parallel.

5) Aligning the cultural aspects of lean with the data driven and project-focused investigations of six-sigma and operator empower rment of TPM, can bring high potential for a comprehensive and sustainable approach to organizational change and process improvement.

6) The methodology of new model can promote the culture of team work and problem solving, which ensure high quality of outcomes.

7) Analogous to traditional manufacturing which is revolutionized by lean concepts, maintenance as a peopledriven function, can be transformed to a predictive and proactive system that provides a reliable process through lean philosophy. Hence, adapting and applying lean manufacturing techniques in maintenance functions enhances the synergistic effects of integrating maintenance excellence and worldclass manufacturing. Moreover, linking maintenance improvements to buffer challenges provides massive gains through leadtime reduction, increasing asset performance and profitability, as well as reducing manufacturing costs as a result of performance improvement.

8) The culture of breaking down the internal barriers between maintenance and manufacturing departments has been conceptually embedded in the model. This culture and values create partnership and authority, which in turn provides required alignment and critical infrastructures to become prepared for adoption of WCM concept.

\section{Application of New Model:}

Manufacturing industries that either initially wants to start their journey towards WCM or those that are at the middle of journey. The developed model can also coherently fit to improvement strategies of organizations that are trying to reach excellence and wish to excel in global scenario. It is believed that this model will reinforce the strategic decisions which have to be made by managers. Specific and new to this model is that, unlike most of the current models that are developed mainly in relation to the needs of larger scale organizations, the proposed model can be regardless of level of skills and size of the company. Given adequate flexibility enables each company to apply and customize the scope of the model based on its requirement, extent of limitations and desired organizational goals.

\section{CONCLUSION}

Since achieving world-class is a moving target, the quest for reaching to such status is not a destination but an ongoing journey that creates more and more improvement opportunities over time. The authors believe that with a minimum combination of strategic concepts (that is - lean, six-sigma and TPM), remarkable level of performance can be achieved in both maintenance and manufacturing arenas. It is remarkable that implementation of the model should be based on an integrated fashion 
rather than a sequential manner, since effective application of each tool is embedded at the heart of other concepts, and also methodology of all tools has spread over every phase of model implementation. This method highlights the significance of reaching to maintenance excellence as an inseparable prestipulation for progressing towards WCM. It must be mentioned that in general, the improvement achieved by implementing the WCM model will take time; one cannot become world-class in all functions overnight. However, genuine commitment and direct involvement of management, followed by the education and empowerment of the employee as strong foundation, can catalyze the change process, yet maximize its effectiveness. The proposed integrated WCM model can be applied in real environmental conditions to test the validity and reliability of the model with proven examples and data. This can be considered as one of the limitations of this study. Hence, it is beneficial to apply the model in different scenarios to understand the effective use of this model by the use of experiments in the real world, or empirically validate and refine the suggestions of the model through a questionnaire survey. The systematic approach presented by Flynn et al. (1990) could be applied to conduct an empirical investigation of WCM across a wide range of manufacturing companies in different industrial sectors with respect to the proposed model. Planning for the questionnaire survey, it should be noted that although obtaining questionnaire data are relatively easy (because of their nature), however, there is difficulty when it comes to vagueness of the obtained analysis. Therefore, the pilot questionnaire and data should try to reduce vagueness of the survey in every step from designing of the questionnaire to analyzing the data.

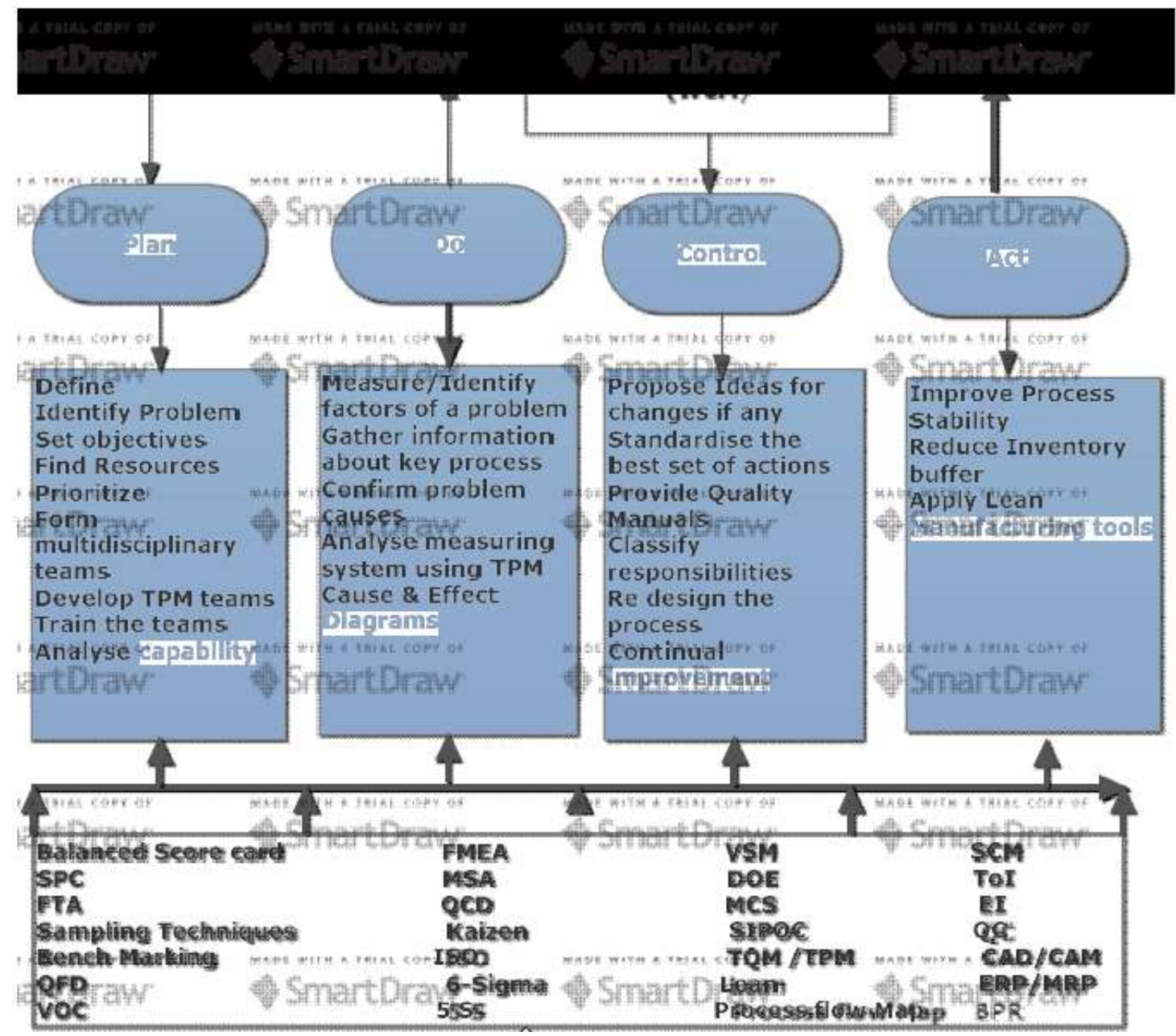




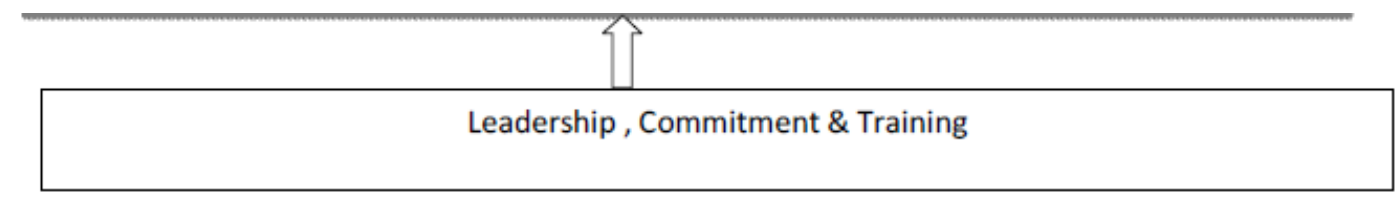

SPC -Statistical Process Control FMEA-Failure Mode \& Effect Analysis VSM-Value Stream Mapping

MSA-Measuring System analysis DOE-Design of Expt Tol-Things of Internet FTA-Fault Tree Analysis

SIPOC-Suppliers input, process, outputs customers

\section{REFERENCES}

[1]. Ahuja, IPS and Khamba, J.S.(2007) An evaluation of TPM Implementation Initiatives in an Indian Manufacturing Enterprise, Journal of Quality in Maintenance Engineering, Vol 13, No.4 pp 338-352

[2]. Al-Mishari ST, Suliman S (2008). Integrating Six-Sigma with other reliability improvement methods in equipment reliability and maintenance applications.

[3]. Antony, J. and Banuelas R (2002) Key ingredients for the effective implementation of Six sigma program Measuring business excellence, Vol. 6, no.4 pp-20-27

[4]. J. Qual. Maint. Eng. 14(1):59-70. Arnheiter ED, Maleyeff J (2005). The integration of lean management and six sigma. TQM Mag. 17(1):5-18.

[5]. Basu R, Wright N (1996). Measuring performance against world class standards. IIE Solut. 28(12):32.

[6]. Bhamu,J. and Sangwan, K.S.(2014) Lean Manufacturing literature review and research issues, International Journal of Operations \& Production Management, Vol. 34, No.7, pp. 876-900.

[7]. Bendell T (2006). A review and comparison of six sigma and the lean organizations. TQM Mag. 18(3):255-62.

[8]. Bowles JB (2004). An assessment of RPN prioritization in a failure modes effects and criticality analysis. J. IEST. 47:51-60.

[9]. Cooper CH (2004). Lean Maintenance for Lean Manufacturing. http://www.plantmaintenance.com/articles/lean_ maintenance_for_lean_manufacturing.pdf. Plant Maintenance Resource Center, Accessed on 20 March 2010.

[10]. Department of Trade and Industry (2004). QCD: Measuring manufacturing performance brochure,

London.http://webarchive.nationalarchives.go v.uk/+/http://www.dti.gov.uk/best practice/operations/quality.htm, accessed on 10 September 2010.

[11]. Eti MC, Ogaji SOT, Probert S (2004). Implementing total productive maintenance in Nigerian manufacturing industries. Appl. Energ.79(4):385-396.
MRP-Material Requirements Planning VOC-Voice of Customer

[12]. Farsijani H, Canuthers A (1996). World Class Manufacturing: Techniques for Implementation for Small and Medium SizedEnterprises. IEMC Proc. Int. Conf. Eng. Technol. Manage. 18(20):112-116.

[13]. Ferrari E, Pareschi A, Persona A, Regattieri A (2002). TPM: Situation and procedure for a soft introduction in Italian factories. TQMMag. 14(6):350-358.

[14]. Finigan T, Humphries J (2006). Maintenance Gets Lean. Ind. Eng. 38(10):26.

[15]. Flynn BB, Sakakibara S, Schroeder RG, Bates KA, Flynn EJ (1990). Empirical research methods in operations management. J.Oper. Manage. 9:250-284.

[16]. Gunn TG (1987). The Fallacy of Directly Pursuing Low Cost in Manufacturing Chief Executive, November/December, New York pp.38-40.

[17]. Harrison A (1998). Manufacturing strategy and the concept of world class manufacturing. Int. J. Oper. Prod. Manage. 18:397-408.

[18]. Hetley S, Catalano J (1999). World-classmanufacturing. Working paper, College of Technology, Bowling Green State University,Bowling Green, OH, USA.

[19]. Kasul RA, Motwani JG (1994). Identification of World Class Manufacturing Factors: A Synthesis of Literature. Int. J. Comm. Manage.4(1/2):50-68.

[20]. Kodali R, Sangwan KS, Sunnapwar VK (2004). Performance Value Analysis for the Justification of World-Class ManufacturingSystems. J. Adv. Manuf. Syst. 3(1):85-102.

[21]. Kumar M, Antony J, Singh RK, Tiwari MK, Perry D (2006). Implementing the Lean Sigma model in an Indian SME: A case study.Prod. Plann. Contr. 17:407-423.

[22]. McCarthy D, Rich N (2004). Lean TPM: A Blueprint for Change. Elsevier, London.

[23]. MilosavljevićP, Rall K (2005). Six Sigma Concept in the Maintenance Process of Technical Systems. Int. J. Mech. Eng. 3:93108.

[24]. Mohammad Amin Okhovat "Development of world class manufacturing framework by using six-sigma, total productive maintenanceand lean" Scientific Research and 
Essays Vol. 7(50), pp. $4230-4241,24$ December, 2012

[25]. Muda S, Hendry L (2002). Proposing a worldclass manufacturing concept for the make-toorder sector. Int. J. Prod. Res. 40(2):353-373.

[26]. Nachiappan RM, Anatharaman N, Muthukumar N (2009). Integrated Approach to Total Productive Lean Six Sigma (TPLSS)Implementation in a Manufacturing Industry. IUP J. Oper. Manag. 8(2).

[27]. Ng K C, Hung I W (2001). A model for global manufacturing excellence. Int. J. Prod. Perf. Manage. 50(2):63-68.

[28]. Okhovat SMA (2010). Development of World Class Manufacturing Model by Using Six Sigma. Total Productive Maintenance andLean. Master Project, University Putra Malaysia. Malaysia.

[29]. Pepper MPJ, Spedding TA (2010). The Evolution of Six Sigma. Int. J. Qual. Reliab. Manage. 27(2):138-155.

[30]. Revere L (2000). Integrating Six-Sigma with total quality management: A case example for measuring medication errors. J. Healthc.Manag. 48(6):377-391.

[31]. Ross DF (1991). Aligning the Organization for World Class Manufacturing. Prod. Inventory Manage. Rev. 32(2):22-28.

[32]. Schonberger RJ (1986). World Class Manufacturing: The Lessons of Simplicity Applied. Free Press, New York.

[33]. Schonberger RJ (1996). World Class Manufacturing: The Next Decade. Free Press, New York.

[34]. Schultz KH (2006). World class manufacturing. Available at: http://ieeexplore.ieee.org/iel3/5238/14154/00 651020.pdf?arnumber=651020 (accessed 25 May, 2012).

[35]. Sharma A (2005). World-class-manufacturing report 2005. Available at: www.cmssoftware.com\ (accessed 25 May 2012).

[36]. Sharma M, Kodali R (2008). Development of a model for manufacturing excellence. Meas. Bus. Excell. 12(4):50-66.

[37]. Sheridan JH (2000). Lean Sigma synergy. Ind. Week 249(17):81-82. Sinha PK, Sinha S (2007). Current Trends in Management.Nirali Prakashan, Pune, India.

[38]. Smith B (2003). Lean and Six Sigma - A onetwo punch. Qual. Progress 36(4):37-41.

[39]. Thomas A, Barton R, Byard P (2008).Developing a Six Sigma maintenance model: Methodology and Theory. J. Qual. Mainten. Eng.14:262-271.

[40]. Wheat B, Mills C, Carnell M (2003). Leaning in to Six-Sigma: A Parable of the Journey to
Six Sigma and a Lean Enterprise.McGrawHill. New York.

[41]. Willmott R, McCarthy D (2000). TPM: A Route to World Class Performance, Butterworth Heinemann, London.

[42]. Womack J, Jones DT (1996). Lean thinking: Banish Waste and create wealth in your cooperation. Simon and Schuster New York. 